\title{
O paradigma clínico-epidemiológico ou biomédico ${ }^{1}$
}

\author{
The clinical-epidemiological or biomedical paradigm
}

KENNETH ROCHEL DE CAMARGO JR.

Universidade do Estado do Rio de Janeiro | UERJ

\begin{abstract}
RESUMO Este trabalho utiliza como ponto de partida o conceito de paradigma, definido por Thomas S. Kuhn como um conjunto de exemplos compartilhados que orientam, sem ser questionados, a atividade do cientista em seu trabalho habitual, comparando-a com outras visões epistemológicas, detendo-se em especial nas críticas levantadas contra este modelo de descrição da atividade científica e continuando a discutir a possibilidade de estendê-lo à epistemologia do conhecimento médico, com base num padrão para a categoria"doença".
\end{abstract}

Palavras-chave paradigma - doença (definição) - clínicas - epidemiologia.

\begin{abstract}
This paper takes as a starting point the concept of paradigm, defined by Thomas S. Kuhn as a set of shared examples that guide, without being reflected upon, a scientist's activity throughout his/hers usual work, comparing it with other epistemological views, considering in detail objections raised against this descriptive model of scientific activity and proceeding on to discuss the possibility of extending such model to the epistemological investigation of medical knowledge, based on a model for the category of "disease".
\end{abstract}

Key words paradigm - disease (definition) - clinics - epidemiology.

\section{Introdução}

0 objetivo deste trabalho é avaliar a possibilidade de aplicação do modelo epistemológico descrito por Thomas Kuhn ao estudo do saber médico ocidental contemporâneo. Com esse propósito, apresentamos um esboço do protótipo kuhniano de desenvolvimento da ciência, suas relações com outras vertentes epistemológicas e ensaio, com base num exemplo concreto, uma aplicação a um saber médico: a clínica.

A tentativa de delimitar uma área de atuação exclusiva para a ciência é no mínimo tão antiga quanto a própria existência do empreendimento cultural subsumido pela palavra "Ciência". Desde seus precursores, seja no plano teórico, como Francis Bacon, seja na definição concreta de um método de experimentação, como Galileu, a exposição de critérios excludentes de produção da verdade tem sido uma constante na história moderna das ciências. ${ }^{2}$ Do ponto de vista filosófico, porém, o marco consensual da formulação pioneira de uma "retaguarda epistemológica" para a ciência emergente é Kant, ${ }^{3}$ de forma tão eficaz a ponto de persistir, ainda hoje, como referência obrigatória neste domínio do saber.

A explicação do que é ou não "ciência", mas poderia ser uma questão meramente semântica, não fosse a questão propriamente política subjacente: quem está autorizado a falar em nome da Verdade? Na tradição religiosa, a verdade provém da instância divina, que se revela com ou sem mediações (profetas, textos sagrados). Os primeiros cientis- 
tas modernos, em especial Newton e Galileu, buscavam ler na Natureza a vontade de Deus, expressa em símbolos matemáticos e Leis universais.4 Com a continuidade do processo de desenvolvimento científico, a busca do divino foi paulatinamente abandonada, colocando-se em seu lugar a própria ciência. Esta passa a ser então a fonte última de revelação da verdade, ou, ainda, na tradição positivista a ciência é, senão verdade, a única certeza possível. ${ }^{5}$ Como mostra Jurgen Habermas, ${ }^{6}$ isto se dá no momento em que o positivismo substitui a teoria do conhecimento de Kant por uma teoria das ciências, em que a reflexão do sujeito cognoscente é substituída pelo debate metodológico. ${ }^{7}$

Desde que, ao longo do processo de transição histórica que culminou no surgimento da racionalidade científica contemporânea, a instância divina foi deslocada no Ocidente como fonte última de legitimação, não só do saber, contudo também - e principalmente - do poder, a interrogação anteriormente colocada assume uma importância crucial do ângulo das lutas pela hegemonia dentro da sociedade: ser o "oráculo da verdade" é uma condição de ascendência indiscutível sobre os demais atores sociais. E, não por acaso, cientistas e filósofos lutam, encarniçadamente, pela manutenção deste território duramente conquistado, tentando mantê-lo inexpugnado, a salvo dos "infiéis". Poucos epistemólogos talvez tenham expressado esta luta de forma mais clara do que Karl Popper, ao defender a ideia de um "critério de demarcação": demarcação territorial e política. ${ }^{8}$ Na concepção de Popper, aquilo que se intitula Ciência, sem sê-lo (como a psicanálise e o materialismo dialético - sic), é pseudociência - e, suponhamos, um engodo. ${ }^{9}$

0 que Popper faz, todavia, é tentar transformar a epistemologia numa metaciência, numa ciência da ciência, responsável última pela definição daquilo que é ou não conhecimento válido. A tentativa de Popper em determinar um critério universal e infalível de determinação da cientificidade supõe a existência de um fundamento absoluto do saber, o que evidencia seu conteúdo cientificista e idealista. É bem verdade que Popper não está sozinho nessa tentativa. ${ }^{10}$ Parece-nos, no entanto, que qualquer tentativa de encontrar fora das ciências um fundamento último que as estabeleça de forma inequívoca, seja lá qual for (o Inconsciente, a História, ou Qualquer Outra Coisa, necessariamente grafada em maiúsculas) deriva para uma reintrodução, pela porta dos fundos, da teologia que gerações prévias de cientistas julgaram ter expulsado pela porta da frente.

\section{A visão de Kuhn}

Thomas Kuhn, físico convertido em historiador das ciências, ${ }^{11}$ apresentou uma visão radicalmente diferente da esboçada anteriormente, tendo causado acalorados debates desde a época da publicação de seu principal trabalho: A estrutura das revoluções científicas. 0 que diz Kuhn de tão polêmico? Partindo da premissa de que a ciência é aquilo que os cientistas fazem, e da observação de que dentro de determinadas disciplinas o consenso é virtualmente unânime com relação às questões básicas do trabalho científico, este autor tenta descrever, numa perspectiva histórica, como, por exemplo, a física se tornou o que é hoje em dia. Cria, assim, uma descrição do modus operandi da ciência, baseada na alternância de fases de consolidação do conhecimento consensual (ciência normal) e de descontinuidade (revoluções científicas). A chave para a produção desta descontinuidade seria dada pela substituição de paradigmas, uma categoria descrita com várias acepções ao longo de toda a obra. Resumidamente, ele seria constituído pelo conjunto de exemplos compartilhados que guiam, sem ser questionados, a atividade do cientista em seu trabalho regular. Esta conceituação inicialmente vaga foi posteriormente aperfeiçoada, ${ }^{12}$ sendo um paradigma definido como uma matriz disciplinar, subdividida em: a) generalizações simbólicas, b) compromissos com crenças em modelos, c) valores e d) exemplos. ${ }^{13}$ Kuhn distingue, portanto, uma fase pré-paradigmática na história das disciplinas, em que o consenso é baixo e as discussões dão-se entre as várias escolas existentes. A partir da aquisição de um primeiro padrão estável, entretanto, as divergências vão paulatinamente desaparecendo, até que se tornam virtualmente inexistentes. ${ }^{14} \mathrm{~A}$ ciência converte-se então em ciência normal, onde as questões metodológicas são assumidas como dadas e a investigação, restringindo sua abrangência, mas ganhando em profundidade, orienta-se para temas progressivamente mais esotéricos. ${ }^{15} \mathrm{~A}$ atividade científica dirige-se para a solução de "quebra-cabeças" 
ou enigmas (puzzles), que extraem seu mérito não de um valor intrínseco, porém da possibilidade de se atingir uma solução, ainda que difícil. ${ }^{16}$ Tipicamente, a solução de um quebra-cabeças científico é concedida pela oportunidade de se prever, de forma cada vez mais precisa, o desenlace de um dado experimento. 0 próprio decorrer desta atividade, contudo, faz surgir anomalias (que só podem ser percebidas como tal contra o fundo das expectativas geradas pela ciência normal, ${ }^{17}$ eventualmente detonando uma crise no interior desta ciência, ${ }^{18}$ resolvida por uma revolução, 0 que implica a substituição do paradigma antigo por um novo). ${ }^{19}$ Kuhn enfatiza o papel da comunidade científica em todo este processo, por algumas características que a diferenciam de outros tipos de comunidade organizada: as comunidades científicas são responsáveis pela sua própria perpetuação, por meio do treinamento dos novos cientistas, e são também aceitas pelos seus membros como o único árbitro possível nas questões de sua prática. Além disso, a comunicação no seu interior é abundante, sendo escassa fora dela, dado o alto grau de especialização e diferenciação de sua linguagem. ${ }^{20}$

A versão aqui delineada, extremamente resumida, do modelo de Kuhn é, evidentemente, empobrecedora, principalmente pela ausência dos incontáveis exemplos históricos dos quais Kuhn se socorre em defesa de suas teses. ${ }^{21}$ Ainda assim, percebe-se quão fundamental na visão de Kuhn (e para o propósito deste trabalho), é a definição do conceito de paradigma e também a descrição da transição entre padrões sucessivos. ${ }^{22}$ Em primeiro lugar, a concepção kuhniana do paradigma pode ser aproximada à de weltanschauung de Max Weber, partilhada neste caso específico apenas por cientistas praticantes de certa disciplina e determinando, entre outras coisas, o que é um problema científico válido, e qual é a forma lícita de resolvê-lo. A natureza gestáltica, extraverbal do paradigma torna-0, a um tempo, indetectável e coator para o pensamento do cientista. ${ }^{23}$ Adicionalmente, no momento em que ele se revela em crise, pela incapacidade de dar conta de algum problema considerado importante pela comunidade, a emergência e eventual triunfo de um novo paradigma não se deve unicamente a uma superioridade lógico-racionalista de um paradigma sobre outro, e sim à capacidade de convencimento da "facção" de um novo. Tal característica, segundo Kuhn, explica-se por serem os paradigmas sucessivos incomensuráveis, isto é, não é possível expressar totalmente um nos termos do outro, e essa incomensurabilidade ${ }^{24}$ é mesmo necessária à evolução de uma dada disciplina. ${ }^{25}$ É claro que esta maior capacidade de convencimento também se deve à chance de oferecer, senão soluções, ao menos perspectivas destas, para as anomalias que colocaram o velho paradigma em crise. É ainda neste sentido que Kuhn afirma a impropriedade da ideia de erro quando se aborda uma formulação teórica: ${ }^{26}$ dentro do âmbito do funcionamento daquele paradigma, uma dada teoria específica já datada era correta e "fez funcionar as engrenagens" da investigação científica. Para que se possa compreender uma determinada formulação teórica, é fundamental que possamos pensar como o cientista de então. Todavia o que é essencial aqui é que, por ter necessariamente um paradigma e também por ser preciso substituí-lo de quando em vez, a atividade científica, consoante Kuhn, não pode ser considerada como um empreendimento puramente racional. A crítica que Imre Lakatos (entre outros) dirige a Kuhn é, a nosso ver, além de injusta, enviesada. Ao dizer que Kuhn faz da transição entre paradigmas um processo "totalmente irracional" (sic), Lakatos ${ }^{27}$ tenta fazer valer sua versão de processo totalmente racional, chegando a invocar Platão nessa defesa. Em suas próprias palavras, seu conceito de "programa de pesquisa" pode ser visto como uma tentativa de redefinir o conceito de paradigma nos termos de um "terceiro mundo" platônico-popperiano: um mundo de "ideias" (Formas?). ${ }^{28}$ Num certo sentido, a maior parte das críticas endereçadas a Kuhn recai neste tópico, o da irracionalidade, o que talvez dê a medida da força e originalidade desta visão. ${ }^{29}$

Mais consequente é a crítica de que Kuhn estaria absolutizando o modelo contemporâneo de ciência, negando 0 processo histórico que o originou, e que ignoraria outros processos sociais que sobredeterminariam a própria atividade científica. Acreditamos que a defesa apaixonada que Kuhn faz da física aristotélica como sendo efetivamente uma física, isto é, tout court uma ciência, parte de um sistema filosófico ${ }^{30}$ responde à primeira ressalva, na medida em que esta declaração evidencia que Kuhn não considera como "ciência" apenas a produção historicamente recente. Quanto à segunda, ainda que rigorosamente exata, pode ser atribuída a uma questão de enfoque. Kuhn preocupa-se em fazer uma história das ciências que não reduza a produção de conhecimento à mera decorrência do processo político e econômico que a superdeterminaria (a chamada abordagem "externalista"), nem apenas mais uma versão do processo 
"cumulativo" do "progresso científico", como é comum na historiografia positivista (abordagem "internalista"). ${ }^{31}$ Por essa razão, elege como objeto de estudo a dinâmica interna da atividade profissional dos cientistas, o ofício destes, por mais que ressalvada a necessidade de complementação de sua abordagem com o estudo dos fatores socioeconômicos que contextualizam a prática da ciência. ${ }^{32}$

\section{Paradigmas e Medicina}

Qual a relevância que este conceito pode ter para a abordagem epistemológica, senão da prática, ao menos do saber médico? Um exemplo de aplicação bastante fértil é dado por Carlo Ginzburg, quando fala de um paradigma indiciário, um modo de produção de conhecimento que se nutriria não das generalizações da versão galileana da ciência, no entanto de uma leitura de sinais que permitiria individualizar casos, padrão este onde, ainda de acordo com Ginzburg, a Medicina estaria situada. ${ }^{33}$

Antes de prosseguir nestas considerações, entretanto, há um imbroglio conceitual que precisa ser desfeito. "Medicina" é uma palavra polissêmica: refere-se a uma prática, a um saber, a uma instituição. Daqui em diante faremos referência, em vez de um termo tão vago, à clínica, disciplina essencial para o par saber/prática na atividade médica. ${ }^{34}$ A leitura do texto de Ginzburg, aliás, permite esta substituição, pois quando fala da medicina, este autor aborda a sua função diagnóstica/classificatória, que é mais propriamente representada pela clínica.

Tendo feito esta ressalva, prossigamos. Embora o médico não seja, senso estrito, um cientista, nem sua atividade profissional usual esteja voltada para a produção do conhecimento, a forma como o saber médico é produzido e transmitido reveste-se, a nosso ver, das características descritas por Kuhn. Assim, mesmo que um médico não esteja fazendo pesquisa quando atende a um paciente, isto não quer dizer que o seu "raciocínio clínico", na expressão de Nelson Blank, ${ }^{35}$ prescinda do paradigma clínico, que faz com que forçosamente o médico procure enquadrar o sofrimento subjetivo do paciente na objetividade asséptica das categorias nosológicas, partindo de uma série de pressupostos denominados anteriormente de teoria das doenças. ${ }^{36} 0$ processo de enquadramento subjacente à proposição de um diagnóstico não é tampouco um processo puramente lógico, racional, baseado em operações conceituais. Diagnosticar é fundamentalmente ver, reconhecer, de uma forma em tudo análoga à ciência normal que Kuhn descreve, e que pressupõe a existência de um (ou mais) paradigma(s).

Sob esta ótica, explicitar em que consiste o paradigma subjacente à racionalidade médica é um passo estratégico na compreensão dos determinantes desta mesma racionalidade.

\section{Uma perspectiva histórica}

A medicina que se origina a partir da anátomo-clínica é uma medicina do corpo, das lesões e das doenças. ${ }^{37}$ É evidente que a incorporação deste referencial à medicina não se deu de forma mecânica, nem imediata; mesmo com a participação fundamental de Vesálio, por exemplo, na "revolução científica", ${ }^{8}$ pela ênfase na observação e na recusa implícita da autoridade dos clássicos (Vesálio teria dedicado vários trechos de seu Humani corporis à crítica de Galeno) a dominação teórica do galenismo e o conservadorismo das corporações médicas garantiram uma sobrevivência considerável das visões medievais sobre a saúde e a doença. Até finais do século XVIII persiste a visão humoralista do processo de saúde-doença, com seus corolários terapêuticos (sangrias, purgantes, vesicatórios), conquanto já acrescida de recursos terapêuticos químicos, contribuição fundamental do controverso Paracelso. ${ }^{39}$

A nova ciência, contudo, aponta para a necessidade de uma nova objetividade, incompatível com a caracterização das doenças baseada apenas na sua sintomatologia. Em 1761 surge o De sedibus de Morgagni, primeiro passo 
de uma trajetória que iria modificar radicalmente a face da medicina no ocidente. Particularmente na França, onde 0 trabalho de Morgagni foi extremamente bem acolhido pela comunidade médica, ${ }_{1}^{40}$ a perspectiva de encontrar-se a essência da doença a partir do exame empírico de lesões delineia todo um novo campo epistemológico. Esta transição corresponde ao processo, apontado por Michel Foucault em 0 nascimento da clínica, de surgimento da anátomo-clínica. Esta delimitação não é, evidentemente, a única possível; Jean Clavreul, ${ }^{41}$ por exemplo, crê poder situar as raízes do pensamento e da prática médica contemporâneos na escola hipocrática. Porém, tomando-se como referencial as dimensões propostas na definição de racionalidade médica, vê-se que a incorporação da anatomia patológica ao arsenal técnico-científico da medicina configura uma ruptura de tal importância que justifica a sua adoção como marco; a medicina do final do século XVIII e a do século XX são muito mais próximas entre si do que de qualquer de seus antecedentes históricos, ainda que possam ter conservado elementos destes. Contudo, apesar de Foucault atribuir um papel preponderante a Bichat neste processo, o mais razoável talvez seja perceber uma trajetória bem menos abrupta que, a partir do trabalho inaugural de Morgagni, e passando pelo próprio Bichat, vai encontrar uma expressão ainda mais característica em Laennec e consolidar-se com Virchow; assim, em vez de uma transição brusca, operada na passagem do século XVIII ao XIX, teríamos um processo de transformação, também radical, todavia mais diluída no tempo, estendendo-se da segunda metade do século XVIII ao final da primeira metade do século XIX.42 Neste processo, consolida-se uma das vertentes da caracterização das doenças, que ao final e ao cabo serão vistas não mais como um fenômeno vital, no entanto como a expressão de lesões celulares. 0 mais fundamental aqui, entretanto, é a mudança de perspectiva que se opera; a nova concepção de doença passa a ser a categoria central do saber e da prática médica.

Este passo, mas não seria possível sem profundas transformações institucionais na prática e no ensino da medicina; eis que a medicina que se delineia a partir deste momento é caracteristicamente hospitalar. ${ }^{43}$ É nos hospitais que se poderá reunir em grande número as observações necessárias ao estabelecimento das descrições anátomo-patológicas; as necrópsias passam a ser efetuadas às centenas. 0 hospital, na virada do século XVIII, não pode ser considerado ainda como uma máquina de tratar, uma vez que os tratamentos eficazes ainda demorarão a ser produzidos; mas certamente já é uma máquina de pesquisa e de ensino. Decerto que estas transformações não podem ser compreendidas fora do contexto social mais geral onde se desenvolvem; para Foucault, por exemplo, a importância dos hospitais como local de tratamento deriva da necessidade de recuperar soldados aptos a manejar o fuzil, que já não seriam tão dispensáveis; a importância da medicina nas cidades só tende a crescer com o processo de migração a partir do campo, na esteira da revolução industrial. Isso talvez explique, ao menos em parte, porque um dos principais polos de desenvolvimento da medicina àquela altura fosse justamente a França.

É claro que a acepção de termos-chave muda em função de modificações mais amplas no conhecimento médico. Observemos as concepções de causa, por exemplo: os primeiros anátomo-patologistas recusavam-se a especular sobre causas do adoecer, julgando-as impossíveis de se conhecer; mais tarde, com o desenvolvimento da microbiologia, num primeiro momento se supôs que praticamente todas as doenças seriam fruto da atividade de micro-organismos; assiste-se atualmente a certa reedição desta perspectiva teórica a partir da biologia molecular - desde o mapeamento genético seria possível reconhecer - e curar - qualquer doença, ou quase. Contudo mesmo na mudança há permanência. Poucas noções terão sido tão fundamentalmente alteradas quanto a de lesão; para os primeiros anátomo-patologistas, as lesões eram teciduais, e o uso do microscópio era veementemente recusado;44 a partir de Virchow a patologia é caracteristicamente celular; Garrod aponta para um erro inato do metabolismo como sendo a característica-chave da alcaptonúria, na virada do século (neste caso, tem-se uma lesão e uma causa, coincidentes num certo sentido); mais tarde Pauling irá demostrar que a lesão da falcemia é uma alteração química da hemoglobina. Ao mesmo tempo, em todas estas definições que se sucedem, há sempre a perspectiva comum da tradução objetiva do ser da doença.

A este desenrolar histórico veio se agregar uma nova vertente ao longo do século $X X$, baseada no estudo de padrões de ocorrência de doenças em populações. Esta expressão caracteriza o nascimento da epidemiologia como disciplina. 


\section{A racionalidade epidemiológica: um esboço}

A epidemiologia tem um papel central na construção das doenças. Ressalta-se, todavia, que o objeto desta seção não é propriamente o saber epidemiológico de um modo geral, no entanto a interface entre esta disciplina e a clínica, lá onde, supomos, surgem as doenças enquanto construção teórica. Note-se, portanto, que não pretendemos abranger o campo disciplinar ou mesmo a metodologia da epidemiologia de modo exaustivo, mesmo porque a leitura de alguns textos críticos ${ }^{45}$ foi suficiente para evidenciar 0 intenso debate metodológico e epistemológico que já se desenrolava neste campo disciplinar. Pretendemos trabalhar aqui não com o estado da arte, entretanto com o saber instituído, não problemático, há muito estabelecido. Com este fim, atenhamo-nos a alguns textos básicos de epidemiologia. ${ }^{46}$ Além destes, foram consultados uma antologia de textos sobre métodos epidemiológicos que cobre três décadas de desenvolvimento disciplinar por meio dos textos selecionados. ${ }^{47}$ Quando necessário, nos reportaremos aos textos críticos já apontados. As questões básicas concernentes à articulação entre as duas disciplinas (clínica e epidemiologia) podem ser abordadas em função da caracterização genérica de uma dada doença e do estabelecimento de nexos causais entre doenças e possíveis agentes etiológicos.

É relevante salientar que dos textos básicos citados apenas Sackett entre outros e Kleinbaum entre outros identificam problemas na definição do que seria uma doença, mesmo assim de uma forma bastante limitada. ${ }^{48}$ Todos, sem exceção, compartilham da visão de doença como entidade, objeto sem história, natural, portanto, tal como proposta pela clínica. É neste sentido que Naomar de Almeida Fo. afirma que a teoria da doença é propriedade da clínica, ${ }^{49}$ conquanto se reconheça o papel da epidemiologia na sua construção.

A crítica epidemiológica se resume à acuidade do diagnóstico, e possíveis variações do mesmo de acordo com 0 método adotado. ${ }^{50}$ Neste particular, o papel da epidemiologia, em especial tal como entendido pelos epidemiologistas clínicos como Sackett, passa a ser apenas o de caracterizar de forma precisa a doença, bem como avaliar processos de identificá-la. Em que pese Foucault ter afirmado que certa teoria geral da ordem, dividida em taxinomia (ordenação qualitativa) e máthêsis (ordenação quantitativa), tenha se exaurido juntamente com a episteme clássica, ${ }^{51}$ acreditamos que a articulação entre clínica e epidemiologia para produzir uma taxonomia das doenças com base em descrições qualitativas e quantitativas se processa em termos no mínimo bastante semelhantes.

0 terreno clássico de atuação da epidemiologia, mas é no estabelecimento de causas. Em face da impossibilidade ou severa limitação imposta à experimentação em anima nobili por óbvios imperativos éticos, ${ }^{52}$ cabe à epidemiologia fornecer à clínica a evidência científica necessária à sua legitimação, por intermédio do estabelecimento de modelos expressos em termos matemáticos - mais exatamente, probabilísticos. ${ }^{53} 0$ estabelecimento de relações causais em epidemiologia pode ser resumido, de forma bastante esquemática, na observação de grupos populacionais diversos, divididos de acordo com a presença ou ausência de fatores e efeitos, usualmente causas e doenças. Uma vez tabuladas as distribuições de uns e outros, e divididos os vários grupos resultantes, ${ }^{54}$ procura-se analisar se há associação significativa do enfoque estatístico entre fator(es) e efeito. Esta significância é alcançada quando a probabilidade de existirem subgrupos com as características observadas for inferior a uma determinada proporção, arbitrariamente escolhida, que define a probabilidade da associação ser puramente aleatória. Embora os processos matemáticos associados à determinação desta significância tenham se sofisticado progressivamente, reforçando a autonomia disciplinar da epidemiologia (com a óbvia contrapartida de torná-la cada vez mais o domínio exclusivo dos experts matemáticos), em especial após o surgimento dos microcomputadores, a lógica geral de inferência estatística é grosso modo a mesma. ${ }^{55}$ Há, porém, um aspecto curioso no estabelecimento de causas por parte da epidemiologia: em todos os textos consultados, as evidências epidemiológicas estão de um modo ou de outro subordinadas ao conhecimento biológico. Isso é menos claro no livro de Sackett, que aborda esta questão apenas à luz da ocorrência de possíveis efeitos adversos da terapêutica, ${ }^{56}$ contudo é bastante clara nos outros dois. ${ }^{57}$ Outro dado relevante diz respeito a como se estabelecem hipóteses etiológicas quando do desenho de estudos epidemiológicos: se por um lado percebe-se uma influência declarada do conhecimento biológico, obviamente há o concurso de toda uma gama de valores não tidos como especificamente científicos na formulação de tais hipóteses. Um exemplo bastante esclarecedor é dado por Eduardo 
Faerstein; ao estudar o discurso epidemiológico sobre o câncer genital feminino, este autor detecta a interferência do que chama de "condicionamentos ideológicos", concluindo que:

(...) há evidência de que a sexualidade feminina é objeto de uma ideologização culpabilizante imiscuída na investigação epidemiológica e na prática de programas, serviços e profissionais de saúde, o que tende a duplicar normas sexuais dominantes. ${ }^{58}$

Encerrando-se este tópico, pode-se observar que, apesar da pujança metodológica da epidemiologia, a produção de conhecimento por esta disciplina encontra-se subordinada à clínica, no momento da definição das doenças (ou "desordens-alvo"), e às ciências biológicas, no estabelecimento e/ou corroboração de suposições etiológicas. Em decorrência dessas subordinações, parece-nos justificada a inclusão da epidemiologia como parte da racionalidade da medicina ocidental contemporânea, submetendo-se, portanto, à mesma cosmologia mecanicista que impregna 0 imaginário científico desta.

\section{A estrutura da doença}

Sob o prisma da formalização teórica, a versão mais aperfeiçoada de um modelo descritivo de doenças em geral é 0 denominado por seus autores de História natural das doenças. ${ }^{59}$ As críticas a este padrão são múltiplas, e não pretendemos repeti-las, visto que o objetivo desta seção é fundamentalmente descritivo. A eventuais objeções de que se trata de uma formulação antiga, responderia apenas que não tendo surgido nada que a suplante parece continuar servindo de embasamento a toda uma série de construções na biomedicina, como pode ser verificado com o mero folhear de qualquer manual médico, por mais contemporâneo que seja. Apresentamos adiante uma adaptação do esquema de Leavell e Clark ${ }^{60}$ sugestivamente denominado por estes autores de "História Natural de Qualquer Processo Mórbido no Homem".

\section{HISTÓRIA NATURAL DAS DOENÇAS}

(Segundo a visão de Leavell e Clark)

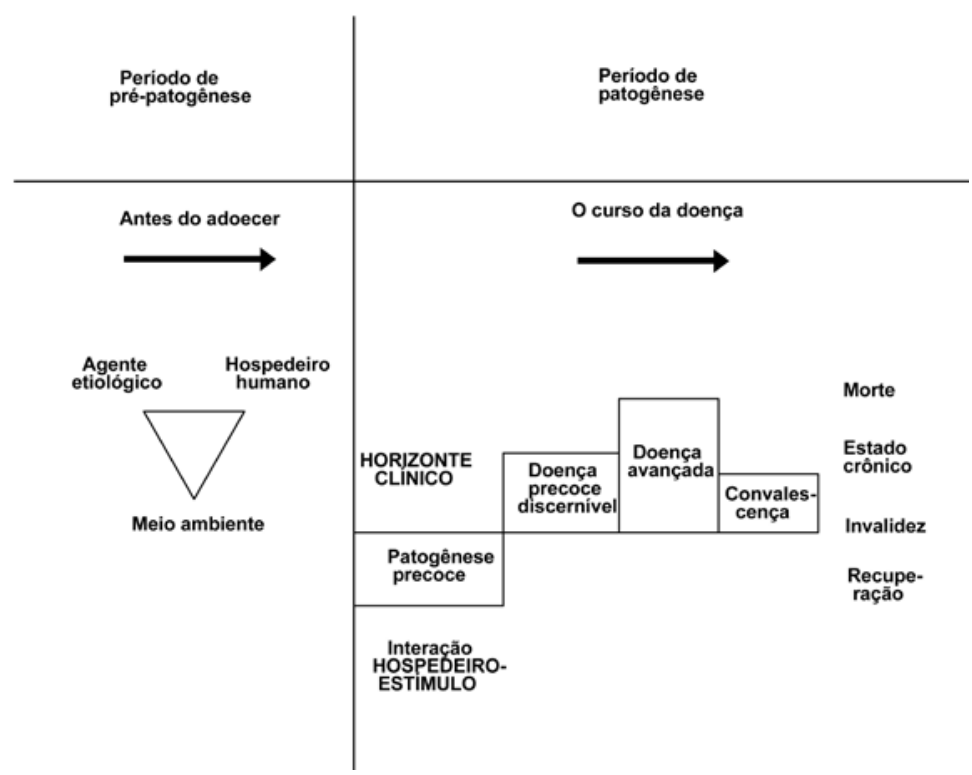


Há vários aspectos dignos de nota neste pequeno esquema; perceba-se, por exemplo, que enquanto o eixo das abscissas é claramente cronológico e quantitativo, o das ordenadas parece intentar representar também de forma quantitativa o processo saúde/doença - no caso, um deslocamento para cima significaria uma "maior quantidade de doença", sendo a quantidade máxima de doença representada pela morte. Outro aspecto fundamental diz respeito à descrição de doenças como processos com causas definidas - ainda que múltiplas - com um transcurso temporal predeterminado.

0 que é importante para os fins deste texto, todavia, é assinalar que ele encerra, no entendimento de seus autores, toda a lógica da intervenção médica - evitar ou retardar a progressão de doenças ou minimizar o dano por elas causado. Mesmo este modelo, no entanto, apesar de descrever o "ciclo de vida" das doenças, não esclarece 0 que viria a ser uma destas criaturas. Novamente observa-se o que já foi descrito anteriormente: não há, no contexto do saber médico, uma conceituação geral do que seria uma doença, entretanto ainda assim é possível identificar um arcabouço genérico de construção discursiva dos elementos desta categoria, que descrevemos originalmente a partir de um estudo histórico sobre a constituição da Aids como categoria diagnóstica61 como sendo constituído por três dimensões ou eixos: 0 explicativo, o morfológico e o semiológico.

Essa é uma descrição que não dá conta, porém, de toda uma classe de doenças definidas a partir de valores numéricos estabelecidas com o início da investigação epidemiológica, cujo protótipo é o da hipertensão. A constituição da hipertensão arterial como categoria diagnóstica se deu com base no célebre estudo de Framingham, ${ }^{62}$ que estabeleceu que níveis médios da pressão arterial acima de determinados valores representavam risco significativamente aumentado de doença coronariana. 0 quadro completo da definição de uma doença ficaria da seguinte forma:

\section{Quadro 1. Eixos de Definição de Categorias Diagnósticas}

\begin{tabular}{lllll} 
Eixos & Epidemiológico & Explicativo & Morfológico & Semiológico \\
\hline Disciplina-tipo & Epidemiologia & Fisiopatologia & Anatomia patológica & Clínica \\
\hline Categoria central & Risco & Causa & Lesão & Caso \\
\hline Definição da doença & Risco significativo & Processo & Expressão de lesão(ões) & Gestalt semiológica \\
\hline Método característico & Observacional/ estatístico & Experimental & Descritivo & $\begin{array}{l}\text { Indiciário/ } \\
\text { observacional }\end{array}$ \\
\hline Período histórico & $\begin{array}{l}\text { Segunda metade } \\
\text { do século XX }\end{array}$ & $\begin{array}{l}\text { Segunda metade } \\
\text { do século XIX }\end{array}$ & Fim do século XVIII/ início do século XIX Século XVIII \\
\hline
\end{tabular}

Na acepção de Foucault, ${ }^{63}$ esta descrição toma as doenças como formações discursivas, e não objetos preexistentes, já que um dos objetivos deste trabalho é justamente proporcionar uma visão crítica desta pressuposição de preexistência. Note-se que ao utilizar o termo "estrutura", referimo-nos apenas ao arranjo de determinadas construções teóricas, não havendo nenhuma pretensão ontológica neste uso.

0 primeiro eixo concerne à possibilidade da definição de doenças como consequência de sinais de risco, antes que lesões detectáveis se expressem. 0 modelo é o da epidemiologia dos fatores de risco, sendo sua primeira realização, conforme já mencionado, o significado de hipertensão como categoria diagnóstica; pela primeira vez na história da medicina definiu-se uma doença a começar da variação numérica de um dado parâmetro (no caso, a pressão arterial), sendo a fronteira normal/patológica determinada por um estudo epidemiológico. Exemplo mais recente é o da hipercolesterolemia, mas mesmo para doenças já descritas anteriormente existe a alternativa de redescrição a partir de valores numéricos - veja-se, como exemplo, o caso do diabetes mellitus. Este é o eixo onde a epidemiologia reina absoluta.

0 segundo corresponde à caracterização das doenças como processo, possuindo uma ou mais causas e uma história natural. Este é o eixo da fisiopatologia, da experimentação em animais, com indução de doenças artificiais. 
É nele que o saber médico mais se aproxima das ciências "duras" no domínio do biológico. Há ainda alguma relação com a epidemiologia, no que diz respeito ao estabelecimento de causas. Este é, por fim, o eixo historicamente mais recente, tendo se desenvolvido desde a segunda metade do século XIX. ${ }^{64}$

0 terceiro é o da descrição de lesões características, patognomônicas, território característico da anatomia patológica. 0 conceito de lesão sofreu modificações basicamente em termos de sua abrangência, acompanhando, como já descrito anteriormente, o movimento geral das disciplinas biológicas em direção ao microscópico; contemporaneamente expõem-se lesões em nível molecular. Assim sendo, a maior parte da parafernália laboratorial utilizada para a realização dos chamados exames complementares estaria incluída neste eixo, visto que tais exames dirigem-se, basicamente, a evidenciar lesões; a exceção estaria nos métodos que produzem grandezas numéricas, que podem figurar no primeiro eixo, sem caracterizar lesão propriamente dita. Historicamente este eixo consolida-se num período que vai do final do século XVIII aos primeiros anos do século XIX.

0 quarto eixo é o da clínica propriamente dita, onde as doenças são vistas como constelações de sinais e sintomas, formando gestalts semiológicas. Este é o eixo da leitura do caso. A sua caracterização no presente não é uma tarefa simples, tendo em vista a imbricação das definições propriamente semiológicas das doenças com os outros dois eixos. Deve-se recordar, contudo, que a grade nosológica hoje representada pela classificação contida no Código Internacional de Doenças (CID) antedata os desenvolvimentos metodológicos contidos nos eixos anteriores. Se, por um lado, utilizando a terminologia foucaultiana, podemos dizer que a medicina das espécies foi suplantada pela anátomo-clínica, isto não equivale a dizer que a medicina tenha deixado de ser classificatória. Ao contrário, no terreno preparado pela taxonomia anteriormente desenvolvida, ainda no século XVIII, é que as instâncias de objetivação desenvolvidas a partir da anátomo-clínica encontraram um campo de desenvolvimento pleno. Fica claro, portanto, que este eixo comporta um avanço simultâneo em duas direções: a da individualização, recorrendo a um método indiciário (tal como descrito por Ginzburg) para recortar uma gestalt semiológica específica; ao mesmo tempo, há um movimento de generalização, localizando o caso individual num inventário de doenças (a grade nosológica a que aludi há pouco) produzido em conformidade com o mesmo método. É nesta segunda direção que a clínica se aproxima da epidemiologia. Mais ainda, se tomarmos epidemiologia, numa definição mínima, como o estudo de doenças em populações, clínica e epidemiologia tornam-se indistinguíveis. É possível dizer que, se abstrairmos o instrumental matemático incorporado pela última neste século, as duas disciplinas confundem-se nas suas origens: o nascimento da clínica foi, também, 0 surgimento da epidemiologia. ${ }^{65} \mathrm{~A}$ separação das duas disciplinas, iniciada posteriormente, ainda hoje é incompleta. Gêmeas xifópagas, clínica e epidemiologia encontram-se ligadas por seu patrimônio comum: a coleção de doenças, construída em conjunto pelas duas.

Essa descrição analítica, todavia, não se traduz por nenhuma operação hierarquizada do pensamento médico; diagnosticar doenças é concebido no pensamento médico antes de tudo como uma questão de percepção ${ }^{66}$ Acreditamos ser possível, em função disso, afirmar que esse modelo é na verdade o coração do chamado paradigma clínico-epidemiológico ou biomédico. É a partir desta concepção da doença que se constrói o acervo de exemplos compartilhados por médicos durante seu aprendizado e exercício profissional, que irá constituir o ponto nodal de seu saber e sua prática.

Tendo discutido a estruturação histórica de um esquema de doença, é possível redescrever a transição operada por Bichat na clínica, que passou com isso a ser anátomo-clínica, na descrição de Foucault, ${ }^{67}$ com uma linguagem kuhniana. Como Foucault assinala, a dissecção de cadáveres deixara há muito de ser interdita, o que impede que se justifique o surgimento da anatomia patológica naquele momento e não anteriormente por uma simples abolição de obstáculos morais ao "progresso da ciência". Antes de Bichat, o paradigma vigente na clínica impedia que o corpo morto fosse incluído no raciocínio clínico como fonte de evidências. Não se tratava simplesmente de dissecar cadáveres, no entanto de necropsiá-los; ou seja, era importante fazer ver o que até então não era visto. Esta seria uma das funções primordiais do paradigma: através de exemplos, fornecer um novo modo de perceber, uma nova gestalt semiológica. Por outro lado, mesmo dispondo de microscópios à mão, Bichat não os apontou para as lesões que descrevia. Uma vez mais, não havia um paradigma que desse suporte a outra inversão gestáltica, desta vez do macro para o microscópico: 
se as lesões eram fenômenos caracteristicamente tissulares, porque procurá-las em "outro lugar"? Este exemplo é duplamente importante: por um lado, parece ser análogo às situações descritas por Kuhn de passagem de uma fase pré-paradigmática para a vigência de um primeiro paradigma; por outro lado, as generalizações envolvidas nele têm sua validade reconhecida até nossos dias, por mais que modificadas: a ideia de que a toda doença corresponde a uma lesão, localizada no corpo é perfeitamente familiar a qualquer médico. Além disso, a utilização do cadáver como instrumento de produção de verdade também persiste como um dos pilares da "ciência médica". Dessa forma, o nascimento da clínica assinalaria, com base na terminologia de Kuhn, o momento em que o saber médico adquiriu seu primeiro paradigma estável. Como o próprio Bichat sugeriu, abriram-se alguns cadáveres, e as dúvidas se dissiparam.

\section{Conclusão}

A possibilidade da utilização do modelo kuhniano (em especial no que tange aos exemplos compartilhados) no estudo do saber médico nos parece demonstrada. Cabe ainda, entretanto, indagar se esta oportunidade traz algo de realmente novo a esta área de investigação.

Pensamos que supor, como Kuhn, a ciência como um empreendimento apenas parcialmente racional, e considerar o paradigma como determinante fundamental na forma como o cientista percebe o mundo (especialmente 0 "mundo" de seu laboratório), abre novas perspectivas no estudo dos paradoxos da clínica.68 Referimo-nos, em especial, ao papel condicionante que as teorias correntes acerca das categorias diagnósticas e de sua gênese têm no modo como o médico traduz o sofrimento que seus pacientes apresentam, supervalorizando os aspectos objetiváveis, traduzidos em doença, e deixando de lado o universo subjetivo do sofrer. Propõe-se como tese que esta dissociação deve-se à existência do paradigma clínico-epidemiológico descrito anteriormente, que condiciona a percepção do médico ao modelo da teoria das doenças. Sendo um paradigma, não é completamente enunciável em termos objetiváveis, e seu aprendizado tampouco se faz por meio de proposições lógicas analiticamente decompostas, mas mediante exemplos. Mesmo atentando para as diferenças do trabalho do médico com relação ao do cientista, acredita-se que a extensão do conceito de paradigma a esta prática profissional é razoável.

Talvez nos domínios da clínica, mais do que em outras disciplinas não tão imediatamente ligadas a necessidades sociais específicas, as implicações desta norma são cruciais. Ao contrário do que ocorre nas chamadas "ciências exatas", cuja metodologia pode ser vista como a expressão prática de ideais de repetibilidade, previsibilidade e exatidão, os saberes da medicina são indissociáveis de um projeto terapêutico, cujos ideais não são totalmente assimiláveis aos da ciência experimental. Ao ser educado na tradição da medicina científica, porém, o médico aprende a ver seus futuros pacientes como meros veículos para as doenças, sendo estas tidas como 0 real objeto de sua prática. Dado 0 caráter coator e extraverbal do paradigma, esta superdeterminação da percepção médica torna-se inatingível apenas pela reflexão crítica do próprio sujeito cognoscente - no caso, o médico. Evidenciar a construção do paradigma clínicoepidemiológico suposto pode ser útil, portanto, na reaproximação da ética expressa no alívio do sofrimento e as formas concretas de exercício profissional da medicina. 


\section{Notas e referências bibliográficas}

Kenneth Rochel de Camargo Jr. é doutor em Saúde Coletiva e professor associado do Instituto de Medicina Social da Universidade do Estado do Rio de Janeiro (IMS/UERJ). E-mail: kenneth@uerj.br

1 Este texto é uma articulação inédita de trabalhos anteriormente publicados isoladamente.

2 KOYRÉ, Alexandre. Estudos de história do pensamento científico. Tradução Márcio Ramalho. Rio de Janeiro: Forense Universitária, 1991. 388 p.; STENGERS, Isabelle. Quem tem medo da ciência? Tradução Eloisa de Araujo Ribeiro. São Paulo: Edições Siciliano, 1989. 175 p.

3 PRIGOGINE, Ilya; STENGERS, Isabelle. A nova aliança. Tradução Miguel Faria e Maria Joaquina Machado Trincheira. Brasília: Ed. Universidade de Brasília 1989. 247 p.; HABERMAS, Jurgen. Conhecimento e interesse. Tradução José N. Heck. Rio de Janeiro: Ed. Guanabara, 1987. 367 p.; STENGERS, Isabelle, op. cit., 1989

$4 \quad$ KOYRÉ, op. cit., 1991, p. 152-180.

5 Assume-se aqui uma acepção abrangente do termo positivismo, consoante a segunda definição apresentada no Vocabulaire de Lalande: "Dá-se por extensão o nome de positivismo às doutrinas que se ligam à de Auguste Comte ou que se lhe parecem, às vezes mesmo de uma maneira bastante distante, e que têm por teses comuns que só o conhecimento dos fatos é fecundo; que a certeza típica é a que é fornecida pelas ciências experimentais; que 0 espírito humano, na filosofia como na ciência, não evita o verbalismo ou o erro a não ser sob a condição de se ter sem cessar em contato com a experiência e de renunciar a todos a priori; enfim, que o domínio das "coisas em si' é inacessível, e que o pensamento só pode dar conta de relações e leis" (LALANDE, André. Vocabulaire technique e critique de la philosophie. 15 ed. Paris: PUF, 1985. p. 792-793).

6 HABERMAS, op. cit., 1987, p. 89.

7 "O positivismo assinala o fim da teoria do conhecimento. Em seu lugar, instala-se uma teoria das ciências. A questão lógico-transcendental acerca das condições do conhecimento possível visava, simultaneamente, à explicação do sentido inerente ao conhecimento enquanto tal. 0 positivismo amputa este questionamento; para ele tal pergunta ficou sem sentido através do fato das ciências modernas. Conhecimento define-se, implicitamente, pelas realizações da ciência. A questão transcendental sobre as condições do conhecimento possível só pode, em consequência, ser ainda colocada na forma de uma inquirição metodológica acerca das regras da montagem e do controle, correspondentes às teorias científicas" (HABERMAS, op. cit., 1987, p. 89). Esta citação abre a parte II de seu livro, cujo capítulo quarto dedica-se especificamente à discussão do positivismo (ibid., p. 89-195).

$8 \quad$ POPPER, Karl. A lógica da descoberta científica. Tradução Leonidas Hegenberg e Octanny Silveira da Motta. São Paulo: Ed. Cultrix, 1989. 567 p.

9 Embora Popper não desqualifique diretamente aquilo que chama "pseudociência", o simples fato de denominar algo de "pseudo" (por mais que não se enuncie explicitamente um juízo de valor no mesmo contexto) é, por si só, uma valoração negativa do objeto em exame.

10 Ver a esse respeito Habermas (op. cit., 1989) e Althusser (ALTHUSSER, Louis. Filosofia e filosofia espontânea dos cientistas. Tradução Elisa Amado Bacelar. Lisboa: Editorial Presença, 1974). Ressaltamos ainda que citamos Popper como caso exemplar. Sua Lógica da descoberta científica é leitura obrigatória para o campo da epistemologia, em que pesem eventuais discordâncias.

11 Kuhn declara explicitamente ter sido inspirado nesta transformação por (entre outros) Koyré, Wittgenstein e Piaget (KUHN, Thomas S. Preface. In: LAKATOS, Imre; MUSGRAVE, Allan (Ed.). The essential tension: Selected studies in scientific tradition and change. Chicago: University of Chicago Press, 1977a. p. IX-XXII.). Um autor particularmente relevante para o próprio Kuhn é Ludwik Fleck; a importância deste último para a obra de Kuhn é de tal ordem que alguns chegam a propor as duas visões como praticamente idênticas, o que relegaria 0 último à posição de reles comentador. Acreditamos, como Mössner (MÖSSNER, N. Thought styles and paradigms - A comparative study of Ludwik Fleck and Thomas S. Kuhn. Studies in History and Philosophy of Science, Londres, v. 42, p. 362-371, 2011) e Braunstein (BRAUNSTEIN, Jean-François. Thomas Kuhn lecteur de Ludwik Fleck. Archives de Philosophie, Paris, v. 66, p. 403-422, 2003-2004), que essa é uma simplificação que não faz jus a nenhum dos dois. Para uma discussão breve - e algo ambíguo - da relevância de Kuhn, ver COLLINS, Harry. Comment on Kuhn. Social Studies of Science. Londres, v. 42, n. 3, p. 420-423, 2012. Sobre a perspectiva teórica Fleckiana, ver, p. ex., CAMARGO JR., Kenneth R. Sobre palheiros, agulhas, doutores e o conhecimento médico: 0 estilo de pensamento dos clínicos. Cadernos de Saúde Pública (FIOCRUZ), Rio de Janeiro, v. 19, n. 4, p. 1.163-1.174, 2003.

12 A segunda edição de $A$ estrutura das revoluções científicas (KUHN, Thomas S. A estrutura das revoluções científicas. Tradução Beatriz Vianna Boeira e Nelson Boeira. São Paulo: Ed. Perspectiva, 1991. p. 225-232) possui um posfácio no qual o conceito de paradigma é mais bem definido - ver a explicação que se segue a esta nota. Este último foi precedido de um texto, "Reconsiderações acerca dos paradigmas" (KUHN, Thomas S. Second thoughts on paradigms. The essential tension: Selected studies in scientific tradition and change. Chicago: University of Chicago Press, 1977c. p. 293-319, p. 354), incluído na coletânea "A tensão essencial". Ambos devem-se basicamente às observações de Margareth Masterman no texto The nature of a paradigm (MASTERMAN, Margaret. The nature of a paradigm. In: LAKATOS, Imre; MUSGRAVE, Allan (Ed.). Criticism and the growth of knowledge. Cambridge: Cambridge University Press, 1970) que faz parte de Criticism and the growth of knowledge, editado por Lakatos e Musgrave, volume dedicado basicamente às controvérsias em torno da obra de Kuhn. Como o próprio Kuhn reconhece (KUHN, op. cit. 1977c. p. 293-319, p. 354), a rigor, a definição está espalhada ao longo de todo o livro, o que equivale a dizer que paradigma, ao menos naquele momento, não era propriamente um conceito.

13 KUHN, op. cit., 1991, p. 225-232.

14 Ibid., p. 37.

15 Ibid., p. 43-55.

16 Ibid., p. 57-66.

17 Ibid., p. 77-92.

18 Ibid., p. 93-105.

19 Ibid., p. 107-171, p. 183-200.

20 Ibid., p. 219-225.

21 Ver no livro $A$ estrutura... (KUHN, op. cit., 1991) os exemplos sobre as teorias elétricas ou a descoberta do oxigênio. Estes dois exemplos, em particular, respondem à crítica de PRIGOGINE; STENGERS (op. cit., 1989, p. 220), de que o retrato que Kuhn faz da atividade científica só se aplica nas circunstâncias 
atuais, quando a pesquisa tem lugar em universidades e institutos de pesquisa. Ambos os exemplos antedatam em alguns séculos esta situação.

22 Um dos objetivos centrais deste artigo é retraçar o conceito de paradigma à obra original de Kuhn, tendo em vista a forma quase aleatória com que essa palavra foi incorporada a um determinado senso comum douto - ver, por exemplo, COULEHAN, Jack. The case of the proliferating paradigms. Qualitative Health Research, Londres, v. 19, n. 10, p. 1.379-1.382, 2009.

23 Há aqui alguma convergência com a noção de filosofia espontânea do cientista Althusser (ALTHUSSER, op. cit., 1974. 202 p., p. 109-130; p. 133-169). Para este autor, o trabalho do cientista é guiado por concepções filosóficas, usualmente não percebidas, formadas por dois componentes, um materialista e 0 outro idealista. A aproximação estaria contida, a nosso ver, na concepção de um arcabouço extracientífico, não refletido, que molda e direciona a atividade de produção científica.

24 Esse conceito encerra outra contribuição original de Kuhn, e também tem sido historicamente um foco de discórdia (para um exemplo recente, ver, por exemplo, DEMIR, Ipek. Incommensurabilities in the work of Thomas Kuhn. Studies in History and Philosophy of Science, Londres, v. 39, p. 133-142, 2008). Por razões de espaço não será possível uma discussão extensa desse conceito; chama-se apenas a atenção para o fato de que, ao contrário do que vários dos seus comentadores (incluindo o supracitado Demir) parecem sugerir, a concepção de incomensurabilidade de Kuhn não é simplesmente outra versão da intradutibilidade Quineana, nem uma afirmação de uma impossibilidade, tout court, de tradução, e sim da necessidade de imersão em um determinado contexto linguístico, em função dos efeitos holísticos da linguagem (KUHN, Thomas S. Commensurability, comparability, communicability. In: LAKATOS, Imre; MUSGRAVE, Allan (Ed.). The road since structure. Chicago: Chicago University Press, 2000. p. 33-57).

25 KUHN, op. cit., 1991, p. 187-199.

26 Ibid., p. 200. De modo correlato, tampouco a ideia de verdade é relevante no trabalho de Kuhn (ibid., p. 213).

27 LAKATOS, Imre. The methodology of scientific research programmes. Cambridge: Cambridge University Press, 1978. 250 p. A respeito das controvérsias envolvendo Kuhn, ver ainda LAKATOS, Imre. Falsification and the methodology of scientific research programmes. In: LAKATOS, Imre; MUSGRAVE, Alan (Ed.). Criticism and the growth of knowledge. Cambridge: Cambridge University Press, 1970; POPPER, Karl. Normal science and its dangers. In: LAKATOS, Imre; MUSGRAVE, Allan (Ed.). Criticism and the growth of knowledge. Cambridge: Cambridge University Press, 1970; FEYERABEND, Paul. Consolations for the specialist. In: LAKATOS, Imre; MUSGRAVE Alan (Ed.). Criticism and the growth of knowledge. Cambridge: Cambridge University Press, 1970. p. 197230; KUHN, Thomas S. Logic of discovery or psychology of research? In: LAKATOS, Imre; MUSGRAVE, Allan (Ed.). Criticism and the growth of knowledge. Cambridge: Cambridge University Press, 1970. p. 1-23; KUHN, Thomas S. Reflections on my critics. Criticism and the growth of knowledge. Cambridge: Cambridge University Press, 1970b. p. 231-278; e o posfácio de A estrutura... (KUHN, op. cit., 1991).

28 "Na verdade (...) meu conceito de 'programa de pesquisa' pode ser entendido como uma reconstrução objetiva, do 'terceiro mundo', do conceito sociopsicológico de 'paradigma' de Kuhn: desta forma o 'deslocamento gestáltico' kuhniano pode ser levado a cabo sem retirar-se os óculos popperianos" (LAKATOS, op. cit., 1978, p. 91, nota 2). 0 "terceiro mundo" a que Lakatos se refere na passagem acima é explicitado no seguinte trecho: "(...) 0 crescimento da ciência se dá essencialmente no mundo das ideias, no 'terceiro mundo' de Platão e Popper, no mundo do conhecimento articulado que é independente do sujeito cognoscente" (ibid., p. 92).

29 Referências adicionais ao trabalho de Kuhn e seu confronto com a visão empírico-racionalista da ciência podem ser encontradas em EPSTEIN, Isaac. Revoluções científicas. São Paulo: Ática, 1988. 144 p.

30 KUHN, Thomas S. Preface. In: LAKATOS, Imre; MUSGRAVE, Allan (Ed.). The essential tension: Selected studies in scientific tradition and change. Chicago: University of Chicago Press, 1977a. Preface, p. IX-XXII.

31 KUHN, Thomas S. The history of science. The essential tension: Selected studies in scientific tradition and change. Chicago: University of Chicago Press, 1977b. p. 105-126.

32 "É evidente que meu livro pouco tem a dizer sobre estas influências externas [do meio social, econômico, religioso e filosófico sobre o desenvolvimento científico], mas não deve ler-se como negando a sua existência. Pelo contrário, pode compreender-se como uma tentativa para explicar por que motivo a evolução das ciências está muito mais isolada, embora não completamente, do respectivo meio social do que disciplinas como a engenharia, o direito e as artes (excetuando-se a música). Além disso, se se ler assim, o livro pode fornecer alguns instrumentos preliminares aos que desejam explorar os caminhos em que e as avenidas através das quais as influências externas se tornaram manifestas" (KUHN, Thomas S. Preface. In: LAKATOS, Imre; MUSGRAVE, Allan (Ed.). The essential tension: Selected studies in scientific tradition and change. Chicago: University of Chicago Press, 1977a. p. IX-XXII, p. XV).

33 GINZBURG, Carlo. Sinais: raízes de um paradigma indiciário. In: Mitos, emblemas, sinais. Tradução Federico Carotti. São Paulo: Cia. das Letras, 1989. p. 143-179.

34 CAMARGO JR., Kenneth R. (Ir)racionalidade médica: os paradoxos da clínica. Rio de Janeiro: IMS/UERJ, 1990. Dissertação (Mestrado em Medicina Preventiva e Social).

35 BLANK, Nelson. O raciocínio clínico e os equipamentos médicos. Rio de Janeiro: IMS/UERJ, 1985. Dissertação (Mestrado em Medicina Preventiva e Social).

36 CAMARGO JR., op. cit., 1990.

37 Ibid., 1990

38 HALL, A. Rupert. A revolução na ciência - 1500-1750. Tradução Maria Teresa Lauro Perez. Lisboa: Edições 70, [1988]. 494 p.

39 HALL, op. cit., p. 121-122.

40 GRMEK, Mirko. La réception du De Sedibus de Morgagni en France au 18e siècle. Dix-huitième siècle, Paris, n. 23, p. 59-73, 1991.

41 CLAVREUL, Jean. A ordem médica: poder e impotência do discurso médico. Tradução Jorge Gabriel Noujaim, Marco Antonio Coutinho Jorge e Potiguara Mendes da Silveira Jr. São Paulo: Brasiliense, 1983. 274 p.

42 ACKERNECHT, Erwin Heinz. La médecine hospitalière a Paris: 1794-1848. Paris: Payot, 1986. 296 p.

43 Ibid., 1986; FOUCAULT, Michel. 0 nascimento do hospital. In: __. Microfísica do poder. Tradução Roberto Machado. Rio de Janeiro: Graal, 1981.

44 ACKERNECHT, op. cit., 1986, p. 24.

45 ALMEIDA Fo., Naomar de. Epidemiologia sem números. Rio de Janeiro: Campus, 1989. 108 p.; ALMEIDA Fo. A clínica e a epidemiologia. Salvador: APCE/ ABRASCO, 1992. 164 p.; COSTA, Dina Czeresnia. (Org.) Epidemiologia - teoria e objeto. São Paulo: HUCITEC/ABRASCO, 1990. 220 p.; AYRES, José Ricardo C. M. A epidemiologia e o projeto emancipador nas práticas de saúde. São Paulo: FMUSP, 1991. Dissertação (Mestrado em Saúde Pública); SCHRAMM, Fermin 
R.; CASTIEL, Luis David. Processo saúde/doença e complexidade em epidemiologia. Cadernos de Saúde Pública, Rio de Janeiro, v. 8, n. 4, p. 379-390, 1992.

46 MacMAHON, Brian; PUGH, Thomas F. Epidemiology: principles and methods. Boston: Little, Brown \& Co., 1970. 376 p.; LILIENFELD, D. Foundations of epidemiology. New York: Oxford University Press, 1980. 375 p.; KLEINBAUM, David G. et al. Epidemiologic research. Belmont, California: Lifetime Learning Publications, 1982. 529 p.; MIETTINEN, Olli. Theoretical epidemiology. New York: John Wiley \& Sons, 1985. 359 p.; SACKETT, D. et al. Clinical epidemiology: a basic science for clinical medicine. Boston: Little, Brown \& Co., 1985. 350 p.

47 GREENLAND, Sander (Ed.) Evolution of epidemiologic ideas: annotated readings on concepts and methods. Chestnut Hills, Mass.: Epidemiology Resources, Inc., 1987. 190 p. - em especial o prefácio à p. v.

48 Estes autores definem doença como "0 desarranjo anatômico, bioquímico, fisiológico ou psicológico cuja etiologia (se conhecida), mecanismos desadaptativos, apresentação, prognóstico e tratamento nós lemos em textos médicos". Mesmo que este elemento seja usualmente chamado de a doença, a utilidade deste termo ambíguo é prejudicada pela inabilidade tanto de pacientes como da desordem-alvo (SACKETT, D. et al. Clinical epidemiology: a basic science for clinical medicine. Boston: Little, Brown \& Co., 1985. 350 p., p. 1). Ou seja, posto que admitindo a ambiguidade do termo, pressupõe-se uma firme correlação do que usualmente se chama "doença" com uma desordem genérica e naturalmente dada. KLEINBAUM et al. (op. cit., 1982, 529 p.) não chegaram a elaborar um conceito de doença (a ênfase de seu livro está nos métodos), e a interpretação que dão é tão confusa que não vale a pena ser transcrita (op. cit., p. 20). Olli Miettinem (Theoretical epidemiology. New York: John Wiley \& Sons, 1985. 359 p.) sequer tentou elaborar um conceito de doença, enfatizando unicamente as "relações entre eventos" (op. cit., p. 1-5).

49 ALMEIDA Fo., op. cit., 1989, p. 17.

50 MacMAHON, Brian; PUGH, Thomas F. Epidemiology: principles and methods. Boston: Little, Brown \& Co., 1970. 376 p., cap. 4 (Classificação de doenças), em especial à p. 47; LILIENFELD, op. cit., 1980, cap. 3 (Conceitos epidemiológicos de doença selecionados), em especial no item D (Espectro da doença), p. 58 e cap. 6 (Estatísticas de mortalidade); SACKETT et. al., op. cit., parte I (Diagnóstico).

51 FOUCAULT, Michel. As palavras e as coisas. Tradução Salma Tannus Muchail. Rio de Janeiro: Martins Fontes, 1990. 407 p., p. 87-91.

52 Ou não tão óbvios, quando se observa o modus operandi da pesquisa farmacêutica com relação a indivíduos do terceiro mundo.

53 KLEINBAUM et al. (op. cit., 1982) supõem a abordagem probabilística como o meio mais adequado de se elaborar hipóteses aproximativas para um "mundo" que é em última análise determinista, mas ao qual os modelos deterministas não se aplicam em função de imperfeições do conhecimento disponível (op. cit., p. 29).

54 Uma forma bastante frequente de apresentação deste modelo é por meio das chamadas tabelas de contingência, onde fatores e efeitos são dispostos em linhas e colunas, assinalando-se nas células resultantes dos cruzamentos as frequências respectivas. A tabela mais simples analisa um único fator e um único efeito, tipicamente a presença/ausência de uma dada causa suposta e a presença/ausência de certa doença. Esta é a chamada tabela $2 \times 2$, exemplo a undante em manuais de epidemiologia clínica.

55 SWARCWALD, Célia L.; CASTILHO, Euclides A. Os caminhos da estatística e suas incursões pela epidemiologia. Cadernos de Saúde Pública, Rio de Janeiro, v. 8, n. 1, p. 5-21, 1992; KLEINBAUM et al., op. cit., 1982, p. 26.

56 SACKETT et al., op. cit., p. 230-233.

57 LILIENFELD, op. cit., 1980, cap. 12 (A derivação de inferências biológicas a partir de estudos epidemiológicos), em especial a discussão sobre os postulados de Koch (p. 292-295); MacMAHON; PUGH, op. cit., cap. 2 (Conceitos de causa). As concepções discutidas no segundo texto, apesar de antigas, são consideradas clássicas na epidemiologia, tendo, portanto, validade até hoje - ver GREENLAND, op. cit., 1987, p. 25.

58 FAERSTEIN, Eduardo. Ideologia, normas médicas e racionalidade epidemiológica: o caso do câncer genital feminino. Cad. IMS, Rio de Janeiro, v. 3, n. 1, p.173-186, 1989.

59 LEAVELL, Hugh; CLARK, E. Gurney. Medicina preventiva. Tradução Maria Cecilia Ferro Donnangelo, Moises Goldbaum e Uraci SimoPes Ramos. São Paulo: McGraw-Hill do Brasil, 1976. 744 p., p. 14-35.

60 LEAVELL; CLARK, op. cit., p. 15.

61 CAMARGO JR., Kenneth R. As ciências da AIDS e a AIDS das ciências. Rio de Janeiro: Relume-Dumará, 1994. 207 p.

62 GREENE, Jeremy A. Prescribing by numbers: Drugs and the definition of disease. Baltimore: Johns Hopkins University Press, 2007. 318 p.

63 "Caso se possa descrever, entre certo número de enunciados semelhante sistema de dispersão, no caso em que entre os objetos, os tipos de enunciação, os conceitos, as eleições temáticas, se possa definir uma regularidade (uma ordem, correlações, posições em funcionamento, transformações), se dirá, por convenção, que se trata de uma formação discursiva (...)". FOUCAULT, Michel. La arqueología del saber. Tradução Aurelio Garzoìn del Camino. Mexico (D.F.): Siglo Veintiuno, 1972. 355 p., p. 62

64 Conquanto tenham existido importantes desenvolvimentos na Fisiologia que antedatam este período, esses não foram incorporados de modo uniforme ou mesmo relevante à prática médica. Ackernecht, por exemplo, cita que Cabanis, respeitável e influente médico-filósofo para a geração de médicos que virtualmente criou a anátomo-clínica em Paris, desprezava a contribuição de outras disciplinas científicas para a medicina, por não trazerem qualquer resultado prático (ACKERNECHT, op. cit., 1986, 296 p., p. 20-21).

65 Foucault, ao final do texto " 0 nascimento do hospital" conclui: "0 indivíduo e a população são dados simultaneamente como objetos de saber e alvos de intervenção da medicina, graças à tecnologia hospitalar. (...) A medicina que se forma no século XVIII é tanto uma medicina do indivíduo quanto da população" (FOUCAULT, Michel. 0 nascimento do hospital. In: Microfísica do poder. Tradução Roberto Machado. Rio de Janeiro: Graal, 1981. p. 99-111.). Lilienfeld, por sua vez, inicia seu livro com a seguinte frase: "A epidemiologia ocupa-se com os padrões de ocorrência de doença em populações humanas e dos fatores que influenciam estes padrões" (LILIENFELD, op. cit., 1980, p. 3), frase que Kleinenbaum e outros repetem quase literalmente: "epidemiologia pode ser vista simplesmente como 0 estudo de doença e saúde em populações humanas" (KLEINENBAUM et al., op. cit., p. 20). Acreditamos que a convergência entre as citações fala por si só.

66 SACKETT et al., op. cit., 1985.

67 FOUCAULT, Michel. 0 nascimento da clínica. Tradução Roberto Machado. Rio de Janeiro: Forense Universitária, 1980. 241 p.

68 CAMARGO JR., op. cit., 1990. [Recebido em Maio de 2013. Aprovado para publicação em Junho de 2013.]

[Recebido em Maio de 2013. Aprovado para publicação em Junho de 2013.] 